\title{
ALGORITMA GENETIK UNTUK OPTIMASI PARAMETER MODEL TANGKI PADA ANALISIS TRANSFORMASI DATA HUJAN-DEBIT
}

\author{
SULIANTO', DAN ERNAWAN SETIONO ${ }^{2}$ \\ Dosen Jurusan Teknik Sipil, Fakultas Teknik, Universitas Muhammadiyah Malang \\ E-mail: sulianto1967@gmail.com
}

\begin{abstract}
ABSTRAK
Kelemahan mendasar dari penerapan Model Tangki adalah pada begitu banyaknya parameter yang nilainya harus ditetapkan terlebih dulu secara simultan sebelum model tersebut diaplikasikan. Kondisi ini menyebabkan Model Tangki dianggap tidak efisien untuk memecahkan masalah-masalah praktis. Penelitian ini merupakan upaya untuk meningkatkan kinerja Model Tangki agar dapat diaplikasikan lebih praktis dan efektif untuk analisis transformasi data hujan menjadi data aliran sungai. Pembahasan dalam penelitian ini difokuskan pada upaya menyelesaikan sistem persamaan Model Tangki Susunan Seri, Susunan Paralel dan Susunan Gabungan dengan memanfaatkan algoritma genetik pada proses optimasi parameternya, sehingga sistem persamaan yang dihasilkan dapat menentukan nilai parameter model optimal secara otomatis pada DAS yang diteliti. Hasil penelitian pada DAS Wonorejo menunjukkan bahwa Algoritma Genetik dapat menyelesaikan proses optimasi nilai parameter Model Tangi dengan baik. Pada generasi ke-150 menunjukkan ketiga model tersebut dapat mencapai konvergen dengan nilai fitness yang hampir sama. Pengujian nilai parameter optimal dengan menggunakan set data testing menunjukkan bahwa Model Tangki Susunan Gabungan berbasis Algoritma Genetik cenderung lebih konsisten dibanding dua jenis Model Tangki lainnya.
\end{abstract}

Kata kunci: algoritma genetik, gabungan, paralel, seri, model tangki

\begin{abstract}
Fundamental weaknesses of the application of Tank Models is on so many parameters whose values should be set first before the model is simultaneously applied. This condition causes the Tank Models is considered inefficient to solve practical problems. This study is an attempt to improve the performance of Tank Models can be applied to more practical and effective for the analysis of the data transformation of rainfall into river flow data. The discussion in this study focused on efforts to solve systems of equations Tank Models Series Composition, Parallel Composition and Combined Composition with the use of genetic algorithms in the optimization process parameters, so that the resulting system of equations to determine the optimal model parameter values are automatically in the studied watersheds. The results showed that the Wonorejo Watershed, Genetic Algorithm to solve the optimization process Tank Models parameter values as well. In the generation150 showed the three models can achieve convergence with similar fitness values. Testing optimal parameter values by using the testing data sets show that the Tank Models Combined composition with Genetic Algorithm-based tend to be more consistent than the other two types of Tank Models.
\end{abstract}

Key words: genetic algorithms, combined, parallel, series, tank model

\section{PENDAHULUAN}

Semua model konseptual untuk transformasi data hujan menjadi data aliran sungai pada dasarnya dikembangkan dari konsep dasar yang sama, yaitu daur hidrologi. Hal yang membedakan antara model satu dengan lainnya terletak pada cara melakukan interpretasi terhadap proses mulai terjadinya hujan sampai menjadi aliran. Model tangki oleh SUGAWARA merupakan salah satu model yang dianggap cukup representatif untuk mempresentasikan hubungan data curah hujan dengan aliran sungai (Setiawan, Fukuda and Nakano, 2003). Kelemahan dari penerapan model ini adalah pada banyaknya parameter yang nilainya harus ditentukan terlebih dulu secara simultan sebelum model tersebut diaplikasikan. Penentuan nilai parameter dalam jumlah yang besar (lebih dari 10 parameter) secara simultan bukanlah pekerjaan yang mudah. Bila nilai setiap parameter bersifat kontinu dan penentuannya dilakukan dengan cara emunerasi tentu akan memerlukan proses yang panjang dan melelahkan. Kondisi ini menjadikan model tangki tidak populer untuk diterapkan pada keperluan-keperluan praktis (Sulianto, 2011).

Tulisan ini difokuskan pada upaya menyelesaikan sistim persamaan model tangki dengan memasukkan proses optimasi pada tahap penentuan nilai optimal dari parameter-parameternya. Hasil yang dicapai 
diharapkan dapat meningkatkan kinerja model tersebut agar dapat diaplikasikan menjadi lebih praktis dan efisien. Teknik optimasi yang dipillih adalah Algoritma Genetik (AG). AG merupakan salah satu metode yang telah teruji tingkat keandalannya dalam pencarian akar-akar persamaan pada sistim persamaan komplek dan berdimensi tinggi (Goldberg DE, 1989). Adapun jenis model tangki yang dibahas adalah model tangki susunan seri, susunan paralel dan susunan gabungan.

Hasil penelitian ini diharapkan dapat menjadi petunjuk awal tentang pemberlakukan teknik pencarian parameter optimal berbasis AG dalam menyelesaikan sistim persamaan model tangki. Melalui pengujian dengan menggunakan set data training dan data testing diharapkan juga dapat diketahui indikator kinerja dari setiap jenis model yang dikembangkan, sehingga keterbatasan dari setiap jenis model tersebut dapat dideteksi.

\section{METODE}

Obyek penelitian adalah daerah aliran sungai (DAS) Bodeng pada titik kontrol Bendungan Wonorejo di Kecamatan Pagerwojo Kabupaten Tulungagung Jawa Timur. DAS Wonorejo memiliki luas 126.03 $\mathrm{km}^{2}$. Kegiatan penelitian dilaksanakan melalui dua tahap, yaitu rancang bangun algoritma dan sistim program aplikasi model tangki berbasis algoritma genetik, serta menguji model yang dihasilkan dengan menggunakan seri data amatan. Sistim program aplikasi model disusun menggunakan bahasa program M-FILE MATLAB 7.0 dengan alasan kepraktisan pada aplikasi grafisnya. Pengujian model menggunakan seri data hidroklimatologi harian tahun 2008 hingga tahun 2010. Seri data hidroklimatologi tahun 2008 dan tahun 2009 digunakan sebagai set data training dan seri data tahun 2010 digunakan sebagai set data testing. Set data training digunakan sebagai masukan dalam proses optimasi untuk menghasilkan nilai parameter optimum. Selanjutnya nilai parameter optimum yang diperoleh tersebut digunakan untuk aplikasi model tangki dalam melakukan transformasi data hujan menjadi data debit. Nilai simpangan berupa RMSE, standar $\mathrm{X}, \mathrm{X}^{2}$, RE dan RR yang diperoleh dari perbedaan nilai debit hasil transformasi dan data debit testing menunjukkan indikator tingkat kinerja model.

\section{HASIL DAN PEMBAHASAN}

\section{Konsep Model Tangki Berbasis AG}

Penerapan AG pada pemecahan kasus ini adalah proses optimasi untuk memperoleh nilai parameter optimal dengan fungsi objective minimasi pada simpangan data debit training dan debit hasil simulasi model tangki. Implementasi algoritma model tangki berbasis AG dalam bahasa program M-FILE MATLAB 7.0 dibagi menjadi sebuah program utama dan 7 (tujuh) buah sub program, yaitu: a) dekode kromosom, b) evaluasi individu, c) inisialisasi populasi, d) linier fitness ranking, e) mutasi, f) pindah silang dan g) roulettwheel (Suyanto, 2005). Semua sub program tersebut merupakan bagian dari aplikasi algoritma genetik standar kecuali pada sub program evaluasi individu. Pada sub program tersebut berisi tentang simulasi model tangki beserta evaluasi indikator kinerjanya yang sekaligus merupakan nilai fitness dari proses perhitungan dalam algoritma genetik. Keterkaitan antar sub-sub program tersebut secara skematis ditunjukkan pada Gambar 1.

Beberapa kaidah yang diterapkan dalam menyusun sistim program aplikasi model tangki berbasis AG adalah:

a) Dekode kromosom, skema pengkodean menggunakan binary enconding di mana setiap gen hanya bisa bernilai 0 atau 1 .

b) Nilai fitness, fungsi objective dari penyelesaian masalah ini adalah minimasi simpangan dari seri data target (data debit training) dengan data hasil simulasi model tangki. Indikator simpangan yang digunakan adalah RMSE, sehingga persamaan fitness untuk masalah ini dirumuskan sebagai berikut:

$$
f=\frac{1}{(h+a)}
$$

di mana:

$\mathrm{f}=$ nilai fitness, $\mathrm{h}=$ RMSE dan $\mathrm{a}=$ bilangan kecil.

c) Seleksi orang tua, menggunakan metode seleksi roulette-wheel (roda-roulette). Sesuai dengan namanya, metode ini menirukan permainan roulette-wheel di mana masing-masing kromosom menempati potongan lingkaran pada roda roulette secara proporsional sesuai dengan nilai fitnessnya. Kromosom yang memiliki nilai lebih besar menempati potongan lingkaran yang lebih besar dibandingkan dengan kromosom bernilai fitness rendah.

d) Pindah silang (crossover), merupakan salah satu komponen terpenting dalam AG. Sebuah kromosom yang mengarah pada solusi yang bagus bisa diperoleh dari proses memindah-silangkan dua buah kromosom. Pindah silang diatur dengan menggunakan suatu probabilitas tertentu (pc), artinya pindah silang bisa dilakukan hanya jika 


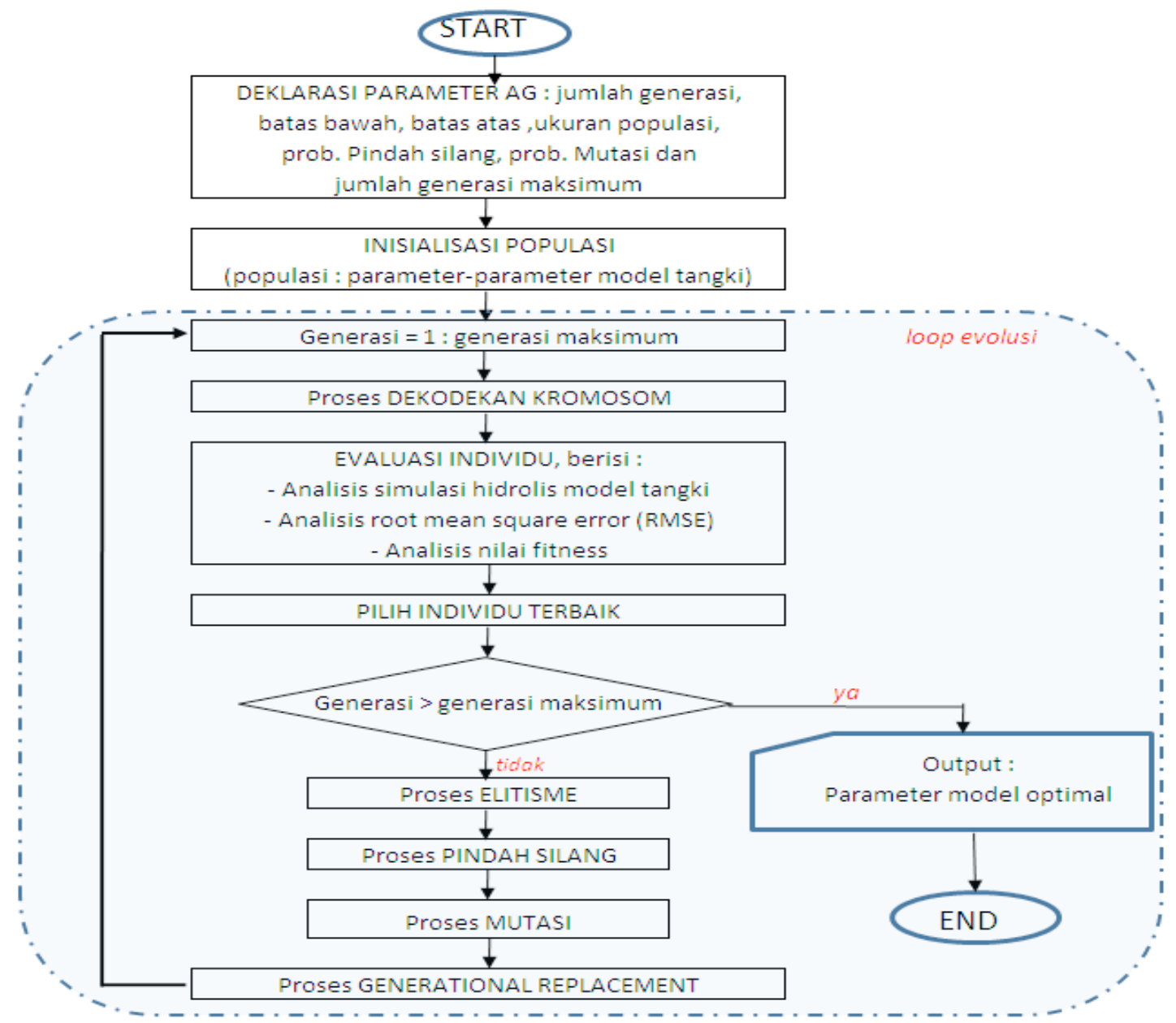

Gambar 1. Diagram Alir Analisis Model Tangki Berbasis Algoritma Genetik

suatu bilangan random $(0,1)$ yang dibangkitkan kurang dari pc yang ditentukan. Pada umumnya pc diset mendekati 1. Cara pindah silang yang dapat digunakan adalah pindah silang satu titik potong (one point crossover), yaitu suatu titik potong yang dipilih secara random.

e) Mutasi, untuk semua gen yang ada jika bilangan random yang dibangkitkan kurang dari probabilitas mutasi pmut yang ditentukan ubah gen tersebut menjadi nilai kebalikannya. Untuk binary enconding, 0 diubah 1 dan 1 diubah menjadi 0 . Biasanya pmut diset $1 / n$, di mana $n$ adalah jumlah gen dalam kromosom. Dengan pmut sebesar ini berarti mutasi hanya hanya terjadi pada sekitar satu gen saja. Dalam kajian ini nilai pmut adalah tetap selama evolusi.

f) Elitisme, merupakan proses mengkopi satu atau beberapa individu. Karena seleksi dilakukan secara random, maka tidak ada jaminan bahwa suatu individu bernilai fitness tertinggi selalu akan terpilih. Kalaupun individu bernilai fitness tertinggi akan terpilih, mungkin saja individu tersebut akan rusak (nilai fitnessnya menurun) karena proses pindah silang. Untuk menjaga agar individu bernilai fitness tertinggi tersebut tidak hilang selama evolusi, maka diperlukan proses elitisme.

g) Penggantian populasi (generational replacement), yang berarti semua individu (misal $\mathrm{N}$ individu dalam suatu populasi) dari suatu generasi digantikan sekaligus oleh $\mathrm{N}$ individu baru hasil pindah silang dan mutasi. Secara umum skema penggantian populasi dapat dirumuskan berdasarkan suatu ukuran yang disebut generational gap G. Ukuran ini menunjukkan persentase populasi yang digantikan dalam setiap generasi. Pada skema generational replacement ini, $G=1$. Skema penggantian yang paling ekstrim adalah hanya mengganti satu individu dalam setiap generasi, yaitu $\mathrm{G}=1 / \mathrm{N}$, di mana $\mathrm{N}$ adalah jumlah individu dalam populasi. Skema penggantian ini disebut sebagai steady-state reproduction. Pada skema tersebut, G biasanya sama dengan $1 / \mathrm{N}$ atau $2 / \mathrm{N}$. Dalam setiap generasi, 
sejumlah NG individu harus dihapus untuk menjaga ukuran populasi tetap $\mathrm{N}$. Terdapat beberapa prosedur penghapusan individu, yaitu penghapusan individu yang bernilai fitness paling rendah atau penghapusan individu yang paling tua. Penghapusan bisa berlaku hanya pada individu orang tua saja atau bisa juga berlaku pada semua individu dalam populasi.

Skema simulasi model tangki susunan seri (standar), susunan paralel dan susunan gabungan ditunjukkan pada Gambar 2, Gambar 3 dan Gambar 4. Pada model tangki standar outflow dari tangki pertama mempresentasikan aliran run off dan sub surface flow, tangki ke dua mempresentasikan intermediate flow, tangki ketiga mempresentasikan sub-base flow dan tangki ke empat mempresentasikan baseflow. Total aliran pada sungai merupakan jumlah dari aliran-aliran tersebut. Pada susunan 4 tangki seri mengandung sebanyak 16 parameter, masing-masing merupakan interpretasi dari tinggi tampungan awal, koefisien lubang serta kedudukan lubang-lubang tangki dari keempat tangki yang diperhitungkan (Sulianto, 2009).

Tangki susunan paralel dianggap presentasi dari suatu DAS yang hanya memiliki sebuah lapisan semi impermeabel terletak di atas dan di bawahnya langsung dibatasi dengan lapisan kedap air. Tangki jenis ini tidak memiliki outlet kearah vertikal oleh karena dalam kenyataannya dianggap tidak ada aliran infiltrasi. Pada kondisi curah hujan terjadi merata di seluruh DAS maka berlaku $\alpha \mathrm{A}=\alpha \mathrm{B}=\alpha \mathrm{C}=1 / 3$. Pada susunan 3 tangki paralel dengan hujan terjadi merata di daerah aliran sungai mengandung sebanyak 12 parameter model. Aliran sungai yang terjadi merupakan penjumlahan dari outlet-outlet tangki, yaitu $\mathrm{Q}=\mathrm{qA} 0+\mathrm{qA} 1+\mathrm{qA} 2$ $+q B 0+q B 1+q C 0$ (Sulianto, 2011).

Tangki susunan gabungan mempresentasikan suatu kondisi DAS yang lebih komplek, di mana sebagian arealnya memiliki karakteristik yang identik dengan penerapan model tangki susunan seri dan bagian lainnya identik dengan penerapan model tangki susunan gabungan. DAS yang memiliki karakteristik ini biasanya memiliki cakupan yang lebih luas. Tangki susunan gabungan memiliki 24 parameter, yaitu: tinggi tampungan awal tangki (SA0, SB0, SC0, SD0), koefisien lubang tangki (CcA0, CcA1, CcA2 untuk tangki A: CcB0, CcB1, CcB2 untuk tangki B: $\mathrm{CcC} 0, \mathrm{CcC} 1, \mathrm{CcC} 2$ untuk tangki C: CcD0, CcD1, CcD2 untuk tangki D), dan kedudukan lubang tangki (Ha1, Ha2, Hb1, Hb2, Hc1, Hc2 dan Hd1, Hd2). Aliran sungai yang terjadi

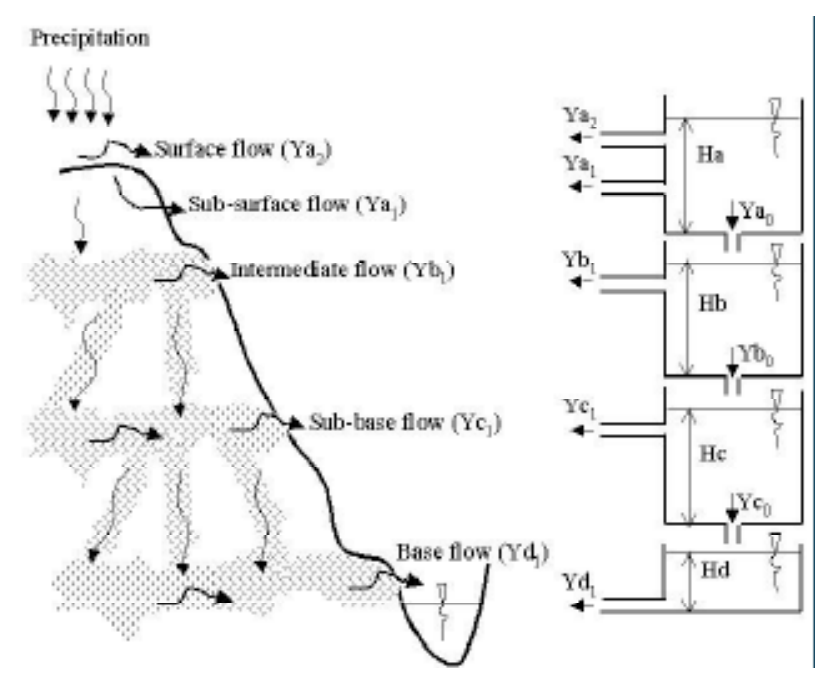

Gambar 2. Konsep Simulasi Model Tangki Standar

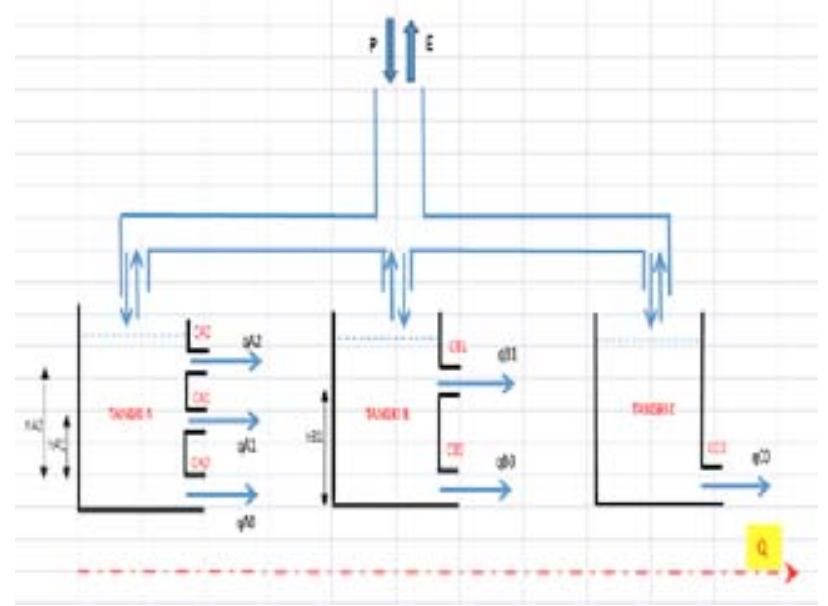

Gambar 3. Konsep Simulasi Model Tangki Susunan Paralel

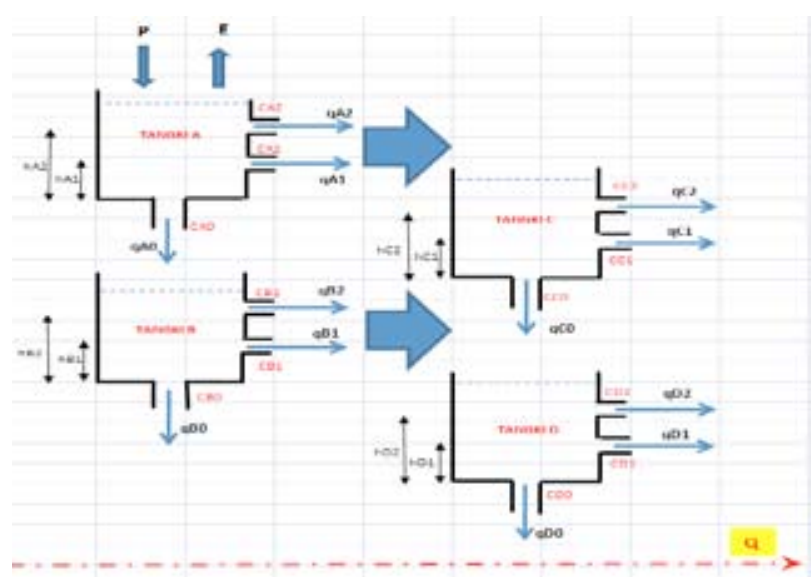

Gambar 4. Konsep Simulasi Model Tangki Susunan Gabungan 
merupakan penjumlahan dari outlet-outlet tangki, yaitu $\mathrm{Q}=\mathrm{qB} 0+\mathrm{qC} 1+\mathrm{qC} 2+\mathrm{qD} 0+\mathrm{qD} 1+\mathrm{qD} 2$ (Shaw and Elizabeth, 1985).

\section{Data Hidroklimatologi}

Data evapotranspirasi diperoleh dari konversi data evaporasi yang tercatat pada stasiun Klimatologi Bendungan Wonorejo. Nilai evapotranspirasi cenderung fluktuatif sesuai musim. Nilai evapotranspirasi rerata yang diperoleh dari konversi data evaporasi amatan tahun 2008 hingga tahun 2010 pada DAS Wonorejo adalah $51.20 \mathrm{~mm} / 10$ hari. Data curah hujan untuk keperluan analisis adalah curah hujan rerata DAS yang nilainya didekati dengan menggunakan metode rata-rata aljabar dengan masukan data hujan titik (point rainfall). Data curah hujan titik adalah data yang terukur pada setiap stasiun penakar hujan. Pada DAS Wonorejo data curah hujan titik yang dilibatkan dalam analisis berasal dari pencatatan stasiun Pagerwojo, stasiun Kampak dan stasiun Tugu. Hasil pencatatan tahun 2008 hingga tahun 2010 menunjukkan musim kemarau rata-rata terjadi pada awal Bulan Mei hingga akhir Bulan Agustus. Tinggi curah hujan DAS Wonorejo Tahun 2008, 2009 dan 2010 berturutturut sebesar $1968 \mathrm{~mm} /$ tahun, $1601 \mathrm{~mm} /$ tahun dan $2734 \mathrm{~mm} /$ tahun.
Data aliran yang dilibatkan dalam penelitian ini merupakan hasil pencatatan debit inflow harian pada automatic water lever record (AWLR) Bendungan Wonorejo Tahun 2008 hingga Tahun 2010. Dari data tersebut menunjukkan bahwa DAS Wonorejo tidak memiliki aliran dasar, oleh karena pada periode musim kemarau terdapat aliran yang bernilai nol. Hasil pencatatan tahun 2008 hingga 2010 menunjukkan debit maksimum terjadi sebesar $48.17 \mathrm{~m}^{3} /$ detik pada akhir Bulan Desember 2010. Nilai aliran rata-rata Tahun 2008, 2009 dan 2010 berturut-turut sebesar 5.16 $\mathrm{m}^{3} /$ detik, $4.21 \mathrm{~m}^{3} /$ detik dan $5.16 \mathrm{~m}^{3} /$ detik. Gambar 5 menunjukkan hubungan antara seri data debit amatan, evapotranspirasi dan curah hujan periode harian tahun 2008 hingga tahun 2010 di DAS Bodeng pada titik control Bendungan Wonorejo.

\section{Implementasi Model Tangki Berbasis AG dengan Masukan Set Data Training}

Tahap ini dianalogikan sebagai langkah pembelajaran model untuk memperoleh nilai parameter optimal. Set data training untuk implementasi model menggunakan data curah hujan, evapotranspirasi dan data aliran sungai Tahun 2008 dan 2009, secara grafis ditunjukkan Gambar 5.

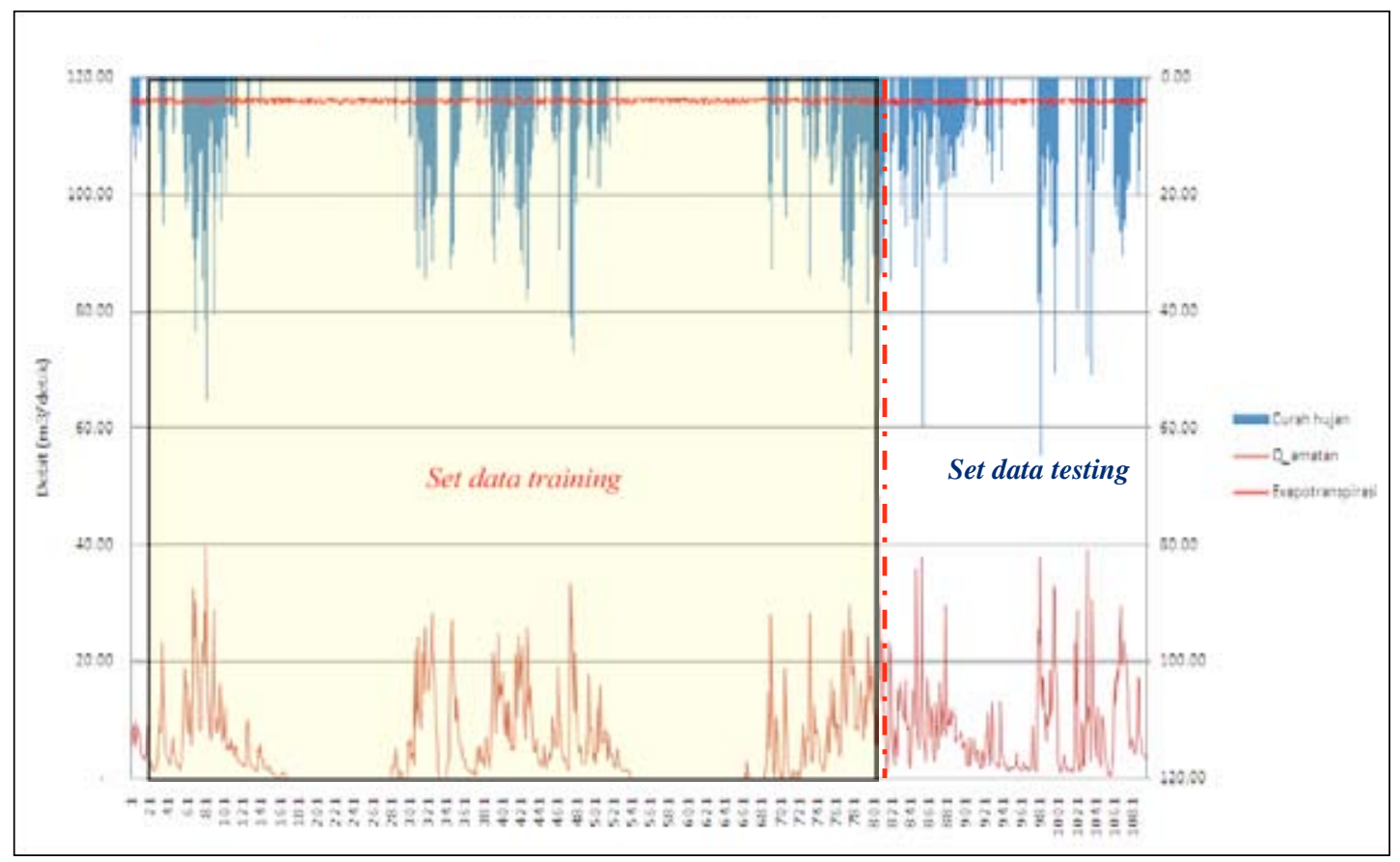

Gambar 5. Data Fluktuasi Q-P-Ep Tahun 2008-2010 di DAS Wonorejo 
Hasil running program Model Tangki berbasis AG dengan masukan set data training, Luas DAS = $126.03 \mathrm{Km}^{2}$ serta parameter algoritma genetik berupa batas bawah $(\mathrm{Rb})=0.0$ : batas atas $(\mathrm{Ra})=50$ : ukuran populasi $(\mathrm{UkPop})=300$; probabilitas pindah silang $($ Psilang $)=0.6$ dan probabilitas mutasi $($ Pmutasi $)=$ 0.01 , proses iterasi mencapai kondisi konvergen pada generasi ke-150. Nilai fitness terbaik untuk model tangki susunan seri diperoleh 0.24 , model tangki susunan paralel sebesar 0.15 dan model tangki susunan gabungan sebesar 0.26. Semakin besar nilai fitness menunjukkan kinerja model semakin baik. Dengan demikian dapat disimpulkan bahwa dengan masukan data training model tangki susunan susunan gabungan terlihat lebih baik dibanding dua jenis model tangki lainnya walaupun perbedaannya tidak terlalu signifikan. Pada nilai fitness tersebut simpangan antara debit luaran model dengan debit data training ditunjukkan pada Tabel 1 . Tabel tersebut mengindikasikan bahwa nilai RMSE, standar $\mathrm{X}, \mathrm{X}^{2}$, RE dan RR yang dihasilkan dari model tangki susunan gabungan cenderung lebih kecil dibanding dua jenis model tangki lainnya. Nilai optimal parameter model dari hasil optimasi berbasis AG diperoleh sebagai berikut:

- Model Tangki Susunan Seri:

$\begin{array}{ll}\text { HA1 }=7.5498 & \text { HA2 }=3.7920 \\ \text { HB1 }=29.1101 & \text { CB } 0=0.7921 \\ \text { CC } 1=0.9807 & \text { HD } 1=15.2030 \\ \text { SC0 }=21.1343 & \text { SD0 }=10.8434\end{array}$

$\mathrm{CA} 0=0.2837$

$\mathrm{CB} 1=0.1048$

$\mathrm{CD} 1=0.8984$

$\mathrm{CA} 1=0.0660$

$\mathrm{HC} 1=18.2064$

$\mathrm{SA} 0=23.3197$

$\mathrm{CA} 2=0.4111$

$\mathrm{CC} 0=0.3519$

$\mathrm{SB} 0=12.8186$

- Model Tangki Susunan Paralel:
$\mathrm{HA} 1=0.0985$
$\mathrm{HA} 2=0.0571$
$\mathrm{CA} 1=0.6072$
$\mathrm{CA} 2=0.3990$
$\mathrm{HB}=0.0751$
$\mathrm{CB}=0.8348$
$\mathrm{HC}=3.8020$
$\mathrm{CC}=0.3210$
$\mathrm{SA} 0=9.5038$
$\mathrm{SB} 0=9.8654$
$\mathrm{SC} 0=3.7698$

- Model Tangki Susunan Gabungan:

$\begin{array}{lllll}\text { HA1 }=1.8319 & \text { HA2 }=1.4391 & \text { CA0 }=0.8482 & \text { CA1 }=0.6722 & \text { CA2 }=0.0189 \\ \text { HB1 }=0.0016 & \text { HB2 }=0.1756 & \text { CB0 }=0.1574 & \text { CB1 }=0.6450 & \text { CB2 }=0.8591 \\ \text { HC1 }=0.6189 & \text { HC2 }=0.4974 & \text { CC0 }=0.9131 & \text { CC1 }=0.0526 & \text { CC2 }=0.2957 \\ \text { HD1 }=1.4426 & \text { HD2 }=0.5246 & \text { CD0 }=0.4206 & \text { CD1 }=0.0069 & \text { CD2 }=0.0445 \\ \text { SA0 }=1.1905 & \text { SB0 }=0.5479 & \text { SC0 }=1.6664 & \text { SD0 }=0.8370 & \end{array}$

Tabel 1. Parameter Kesesuaian Model dengan Data Training

\begin{tabular}{lccccc}
\hline \multirow{2}{*}{ Parameter Statistik } & \multirow{2}{*}{ Satuan } & Debit & \multicolumn{3}{c}{ Debit Luaran Model Tanki } \\
\cline { 4 - 6 } & & Amatan & Seri & Paralel & Gabungan \\
\hline Rerata & $\mathrm{m}^{3} /$ detik & 4.68 & 4.02 & 4.80 & 3.85 \\
Maksimum & $\mathrm{m}^{3} /$ detik & 39.81 & 42.89 & 63.55 & 40.37 \\
Minimum & $\mathrm{m}^{3} /$ detik & 0.00 & 0.00 & 0.00 & 0.00 \\
Standar deviasi & $\mathrm{m}^{3} /$ detik & 6.62 & 7.24 & 9.47 & 6.82 \\
Root Mean Square Error $(\mathrm{RMSE})$ & $\mathrm{m}^{3} /$ detik & & 0.079 & 0.157 & 0.076 \\
Standar X (X) & & & 0.621 & 0.845 & 0.599 \\
Square standar X (X) & & & 0.865 & 1.599 & 0.809 \\
Relatif Error $(\mathrm{RE})$ & & & 0.729 & 0.794 & 0.717 \\
Square Relative Error $(\mathrm{RR})$ & & & 0.684 & 0.761 & 0.667 \\
\hline
\end{tabular}




\section{Uji Parameter Model dengan Menggunakan Set Data Testing}

Uji ini dimaksudkan untuk mengetahui tingkat konsistensi dari nilai parameter model optimal yang telah dihasilkan dari tahap sebelumnya. Pengujian dilakukan dengan menggunakan masukan nilai parameter model optimal dan set data testing. Hasil uji performa model ditunjukkan pada Tabel 2 dan Gambar 6. Memperhatikan nilai dari setiap indikator kinerja seperti ditunjukkan Tabel 1 dan Tabel 2, terlihat tidak terjadi perbedaan yang signifikan. Kondisi ini menunjukkan bahwa nilai parameter model yang dihasilkan dari proses optimasi berbasis AG adalah konsisten dan optimal.

Pada Tabel 2 juga tampak adanya kecenderungan bahwa model tangki susunan gabungan memiliki performa yang lebih baik dibanding dua jenis model tangki lainnya. Dari semua indikator kinerja model berupa RMSE, Standar X, $\mathrm{X}^{2}$, RE dan RR

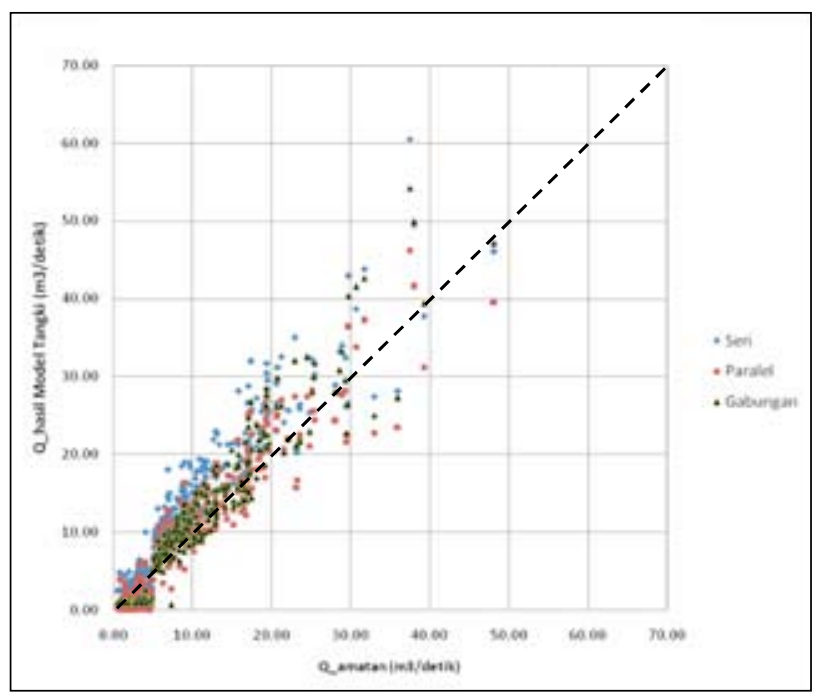

Gambar 6. Hubungan Debit Amatan dan Luaran Model Tangki dari Data Testing juga menunjukkan bahwa model tangki susunan gabungan memiliki nilai paling kecil. Ini berarti simpangan data debit hasil luaran model tangki susunan gabungan dengan data debit testing relative lebih kecil dibanding dua jenis model tangki lainnya. Sebaran dari plot data debit hasil luaran model dan data testing seperti ditunjukkan Gambar 6 menunjukkan kecenderungan bahwa model tangki susunan gabungan lebih mendekati garis persamaan dibanding dua jenis model lainnya. Kondisi ini mengindikasikan bahwa model tangki susunan gabungan berbasis AG lebih relevan untuk sebaran data DAS Wonorejo dibanding dua jenis model tangki lainnya.

\section{SIMPULAN}

Teknik optimasi berbasis AG terbukti dapat meningkatkan kinerja model tangki dalam analisis transformasi data hujan menjadi data debit. Dengan memanfaatkan kelebihan AG maka penerapan model tangki menjadi lebih praktis karena pada proses training model untuk menghasilkan parameter optimal dapat dilakukan lebih dan dapat ditemukan secara otomastis. Aplikasi model tangki berbasis AG dengan masukan set data training dicapai kondisi optimal pada generasi ke-150. Pada generasi tersebut diperoleh nilai fitness terbaik untuk model tangki susunan seri sebesar 0,24, Model tangki susunan paralel sebesar 0,15 dan model tangki susunan gabungan sebesar 0,26. Dari indikator tersebut menunjukkan bahwa model tangki susunan gabungan berbasis AG memiliki kinerja lebih baik dibanding model tangki susunan seri dan model tangki susunan gabungan.

Uji konsistensi nilai parameter model yang dihasilkan dari proses optimasi berbasis AG dengan menggunakan set data testing menghasilkan nilai indikator kinerja yang tidak berbeda jauh dengan

Tabel 2. Parameter Kesesuaian Model dengan Data Testing

\begin{tabular}{|c|c|c|c|c|c|}
\hline \multirow{2}{*}{ Parameter Statistik } & \multirow{2}{*}{ Satuan } & \multirow{2}{*}{$\begin{array}{c}\text { Debit } \\
\text { Amatan }\end{array}$} & \multicolumn{3}{|c|}{ Debit Luaran Model Tanki } \\
\hline & & & Seri & Paralel & Gabungan \\
\hline Rerata & $\mathrm{m}^{3} /$ detik & 9.30 & 12.36 & 9.36 & 9.79 \\
\hline Maksimum & $\mathrm{m}^{3} /$ detik & 48.17 & 60.52 & 46.17 & 54.26 \\
\hline Minimum & $\mathrm{m}^{3} /$ detik & 0.50 & 2.54 & 0.00 & 0.71 \\
\hline Standar deviasi & $\mathrm{m}^{3} /$ detik & 7.81 & 9.63 & 8.56 & 9.47 \\
\hline Root Mean Square Error (RMSE) & $\mathrm{m}^{3} /$ detik & & 0.242 & 0.152 & 0.159 \\
\hline Standar X (X) & & & 1.164 & 0.862 & 0.770 \\
\hline Square standar $\mathrm{X}\left(\mathrm{X}^{2}\right)$ & & & 2.000 & 1.037 & 0.847 \\
\hline Relatif Error (RE) & & & 0.482 & 0.403 & 0.328 \\
\hline Square Relative Error (RR) & & & 0.437 & 0.290 & 0.158 \\
\hline
\end{tabular}


hasil yang diperoleh dari running menggunakan masukan data training. Kondisi ini menunjukkan bahwa nilai parameter model hasil dari proses optimasi berbasis AG adalah konsisten dan optimal. Memperhatikan indikator kinerja dari setiap jenis model yang dihasilkan dengan masukan set data testing, tampak nyata bahwa model tangki susunan gabungan berbasis AG cenderung lebih relevan untuk sebaran data DAS Wonorejo dibanding jenis model tangki lainnya.

\section{UCAPAN TERIMA KASIH}

Penulis mengucapkan terima kasih kepada Universitas Muhammadiyah Malang melalui DP2M-UMM dan DITJEN DIKTI DEPDIKNAS RI yang telah memberikan segala fasilitas atas terselenggaranya penelitian ini melalui program penelitian HIBAH BERSAING Tahun 2011, PERUM JASA TIRTA I Malang atas kerja samanya dalam penyediaan data dan semua pihak yang telah memberikan segala masukan untuk penyempurnaan penelitian ini.

\section{DAFTAR PUSTAKA}

Goldberg D.E, 1989. Genetic Algorithms in Search, Optimization and Machine Learning, AddissonWesley Publishing Co.

Louis J.S., 1993. Genetic Algorithms as a Computational Tool for Design.

Mitchel, M., 1996. An introduction to genetic algorithms, MIT Press.

Shaw M. and Elizabeth, 1985. Hydrology in Practice, Van Nostrand Reinhold (UK) Co. Ltd.

Setiawan, Fukuda and Nakano, 2003. Developing Procedures for Optimization of Tank Models Parameter, The CIGR Journal of Scientific Research and Development, Manuscript LW 01006.

Sulianto, 2009. Algoritma Genetik Untuk Meningkatkan Kinerja Model Tangki Standar Pada Analisa Transformasi Data Hujan Menjadi Data Aliran Sungai, Laporan Penelitian, PBP-UMM, Malang.

Sulianto, 2011. Algoritma Genetik Untuk Meningkatkan Kinerja Model Tangki Pada Analisa Transformasi Data Hujan Menjadi Data Aliran Sungai, Laporan Penelitian Hibah Bersaing, UMM-Malang.

Suyanto, 2005. Algoritma Genetik dalam MATLAB, ANDI, Yogyakarta, Indonesia. 